\title{
Erratum to: Contribution of clinical and socioeconomic factors to differences in breast cancer subtype and mortality between Hispanic and non-Hispanic white women
}

\author{
María Elena Martínez ${ }^{1,2}$ (D) Scarlett L. Gomez ${ }^{3,4} \cdot$ Li Tao $^{3} \cdot$ Rosemary Cress $^{5}$. \\ Danielle Rodriguez $^{5} \cdot$ Jonathan Unkart $^{6} \cdot$ Richard Schwab $^{7} \cdot$ Jesse N. Nodora $^{1,2}$. $^{2}$

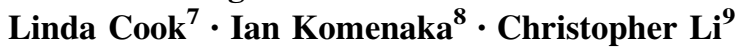

Published online: 4 September 2017

(C) Springer Science+Business Media, LLC 2017

\section{Erratum to: Breast Cancer Res Treat DOI 10.1007/s10549-017-4389-z}

In the original publication of the article, one of the funding sources was missed out inadvertently in the funding information. The authors would like to include the funding source, CA132384 since it is a Partnership grant and needs to be acknowledged as a source of funding.

The online version of the original article can be found under doi:10.1007/s10549-017-4389-z.

María Elena Martínez

e8martinez@ucsd.edu

1 Moores Cancer Center, University of California, San Diego, 3855 Health Sciences Dr., \#0901, La Jolla, CA 92093-0829, USA

2 Department of Family Medicine and Public Health, University of California, San Diego, La Jolla, CA, USA

3 Cancer Prevention Institute of California, Fremont, CA, USA

4 Stanford Cancer Institute, Palo Alto, CA, USA

5 California Cancer Registry, Public Health Institute, Sacramento, CA, USA

6 Department of Surgery, University of California, San Diego, La Jolla, CA, USA

7 Department of Internal Medicine, University of New Mexico and the University of New Mexico Comprehensive Cancer Center, Albuquerque, NM, USA

8 Maricopa Medical Center, Department of Surgery, Phoenix, AZ, USA

9 Division of Public Health Sciences, Fred Hutchinson Cancer Research Center, Seattle, WA, USA 